\title{
MODO VERBAL EN LAS ORACIONES INTERROGATIVAS INDIRECTAS
}

Dentro de las oraciones subordinadas sustantivas se puede distinguir un grupo especial, las interrogativas indirectas. Estas oraciones se introducen con un pronombre o adverbio interrogativo o con la partícula $s i$, que dependen de un verbo de entendimiento o habla como saber, preguntar, decir o ver ${ }^{1}$. En los ejemplos (1) y (2) hay dos oraciones interrogativas indirectas dependientes del verbo de habla decir, en las que la subordinada se encabeza con un pronombre interrogativo y la partícula si, respectivamente:

(1) Dijo cuántos años tenía 2 .

(2) Preguntó si estábamos ocupados ${ }^{3}$.

Las gramáticas del español moderno afirman, en general, que en las interrogativas indirectas se emplea el indicativo ${ }^{4}$ por-

${ }^{1}$ Véanse Gramática descriptiva de la lengua española, eds. I. Bosque y V. Demonte, Espasa-Calpe, Madrid, 1999, t. 2, p. 2154; R. SARmiento, y A. SÁnchez, Gramática básica del español. Norma y uso, SGEL, Madrid, 1989, p. 269.

${ }^{2}$ En los ejemplos que se citan el verbo de la oración principal y el de la subordinada están en cursivas. Si se trata de una forma de subjuntivo en la subordinada ésta va en mayúsculas. La partícula que introduce la subordinada aparece en negritas. El ejemplo, de Gramática descriptiva de la lengua española, t. 2, p. 2152.

${ }^{3}$ Loc. cit.

${ }^{4}$ Cf. J. Borrego, J. G. Asencio, y E. Prieto, El subjuntivo. Valores y uso, SGEL, Madrid, 1987, p. 112; J. Fernández Álvarez, El subjuntivo, Edelsa, Madrid, 1987, p. 47; F. MatTe Bon, Gramática comunicativa del español, Difusión, Madrid, 1992, t. 1, p. 64; M. Molho, Sistemática del verbo español, Gredos, Madrid, 1975, p. 416; Gramática descriptiva de la lengua española, t. 2, pp. 2184, 2185; Sarmiento y SÁnchez, op. cit., p. 269. 
que se trata de transposiciones de oraciones interrogativas directas en las que también se suele usar el indicativo, o porque se formulan para solicitar información ${ }^{5}$.

Esto sucede también si la oración principal está negada, condición que con los verbos de entendimiento y habla suele causar un subjuntivo en la subordinada si la introduce la partícula $q u e^{6}$. Compárense los ejemplos (3) y (4) en los que (3) muestra una interrogativa indirecta que depende de una oración principal negada cuyo verbo de entendimiento es comprender y (4), una subordinada sustantiva introducida por que que también depende de un verbo de entendimiento (mencionar) negado:

(3) No comprendo qué le has podido decir7.

(4) No mencionó que JUGARANal golf 8 .

Sin embargo, R. Woehr ${ }^{9}$, en un corpus de veintiún textos del español antiguo, y Keniston ${ }^{10}$, en uno del siglo xvI, señalan que antes se empleaba tanto el indicativo como el subjuntivo en las oraciones interrogativas indirectas negadas, aunque el indicativo era más común. De ahí que en el español del siglo xvi encontremos ejemplos como:

(5) yo no sé por qué razón lo pide ${ }^{11}$.

(6) ni entiendo cómo te PUEDA querer más ${ }^{12}$.

Parece, por lo tanto, que a lo largo de la historia del español ha habido un proceso de cambio en el que se ha perdido la

${ }^{5}$ Cf. Sarmiento y Sánchez, loc. cit., y Matte Bon, op. cit., t. 1, p. 64.

${ }^{6}$ Fernández Álvarez, op. cit., p. 47; Matte Bon, op. cit., t. 1, p. 59. La Real Academia Española, en su edición de 1962, Gramática de la lengua española, Espasa-Calpe, Madrid, p. 338, sostiene que estas oraciones negadas se construyen con subjuntivo; sin embargo, en su edición más reciente (Gramática descriptiva de la lengua española, t. 2, p. 2026) afirma que puede aparecer el subjuntivo, aunque el indicativo es igualmente posible.

${ }^{7}$ Fernández Álvarez, op. cit., p. 47.

8 Ibid., p. 31.

9 "Syntactic atrophy and the indirect interrogative in Spanish", Studia Neophilologica, 49 (1977), p. 319.

10 The syntax of Castilian prosa, the Sixteenth Century, The University of Chicago Press, Chicago, 1937, p. 391.

11 Ibid., p. 348.

12 Ibid., p. 392. 
variación de modo -indicativo o subjuntivo- en las oraciones interrogativas indirectas, tema que propongo estudiar más en detalle en este artículo.

Para mayor claridad y porque al reunir el corpus de ejemplos resultó ser el verbo más frecuente en los textos, me limitaré a estudiar el modo verbal de las interrogativas indirectas que dependen del verbo de entendimiento por excelencia, saber, precedido por una negación. Concretamente, me interesan oraciones que presentan la estructura (7):

(7) negación - saber - interrogativo/si + verbo conjugado

\section{LAS INTERROGATIVAS INDIRECTAS EN EL ESPAÑOL ANTIGUO Y MODERNO PENINSULAR}

Como primer paso he reunido un corpus de textos del español antiguo y del español moderno en el que todos los casos presentan la estructura de (7).

El corpus del español antiguo consta de cuatro textos ${ }^{13}$ que abarcan las últimas décadas del siglo xv hasta la segunda mitad del siglo xvi. Los cuatro textos se suceden por lo que se refiere al año de edición, con un lapso entre ellos de por lo menos catorce años. He seleccionado este período porque es importante para la formación del español ${ }^{14}$ y porque la lengua del siglo XVI suele considerarse, generalmente, como la base del español de América ${ }^{15}$, del que más adelante estudiaré un dialecto específico. Los cuatro textos se caracterizan por el uso frecuente del estilo directo, debido a la alta proporción de diálogo que contienen y, en el caso de Fernando del Pulgar, al género epistolar;

${ }^{13}$ F. DE Rojas, Celestina. Tragicomedia de Calisto y Melibea, ed. M. Marciales, University of Illinois Press, Urbana-Chicago, [1499, la ed. consultada, de 1514] 1985; F. Delicado, La lozana andaluza, ed. B. Damiani, Castalia, Madrid, [1528] 1969; F. Del Pulgar, Letras, en Letras. Glosa a las Coplas de Mingo Revulgo, ed. J. Domínguez Bordona, Clásicos Castellanos, Madrid, [14731484; la ed. consultada, de 1486] 1929, pp. 1-155; y J. DE VALDÉs, Diálogo de la lengua, ed. C. Barbolani, Cátedra, Madrid, [1535; la ed. consultada, de la segunda mitad del s. XvI] 1982.

14 Cf. por ejemplo R. LAPEsA, Historia de la lengua española, Gredos, Madrid, 1981, pp. 280 ss.

15 Cf. J. G. Moreno de Alba, El español en América, F.C.E., México, 1988, p. 19. 
estas características garantizan la presencia de la estructura que me interesa.

El corpus del español moderno consta de dos textos, una novela contemporánea, La tabla de Flandes de Arturo Pérez-Reverte, y una serie de entrevistas con madrileños hechas en la segunda mitad de la década de $1960^{16}$. Estas entrevistas fueron realizadas en el marco del "Proyecto de estudio coordinado de la norma lingüística culta de las principales ciudades de Iberoamérica y la Península ibérica" de la Comisión de Lingüística Iberoamericana. Los dos textos difieren por lo que hace al género - transcripción de entrevistas, es decir de lengua oral producida en un contexto comunicativamente natural y un texto literario, es decir lengua escrita con fines artísticos. Sin embargo, ambos textos tienen en común el uso frecuente de diálogos, lo que de manera particular los hace apropiados para la presente investigación.

Además, más adelante me referiré a un cuento del escritor español contemporáneo Juan Marsé ${ }^{17}$. A pesar de que dicho texto no ha formado parte del corpus básico, por no presentar sino dos casos de la estructura (7), citaré uno de ellos que a mi parecer sirve muy bien para reforzar el razonamiento expuesto aquí.

El corpus seleccionado permite comprobar si las observaciones de las gramáticas citadas arriba y las de Woehr ${ }^{18}$ y Keniston ${ }^{19}$ acerca del modo verbal de las interrogativas indirectas en el español moderno y antiguo respectivamente se reflejan de manera sistemática en los textos escritos.

En las Tablas 1 y 2 se presentan los datos relevantes:

16 A. Pérez-Reverte, La tabla de Flandes, Alfaguara, Madrid, 1998; M. Esgueva, y M. Cantarero, El habla de la ciudad de Madrid, Instituto Miguel de Cervantes-CSIC, Madrid, 1981.

17 J. MARsé, "El caso del escritor desleído", en Cuentos de La Isla del Tesoro, Alfaguara, Madrid, 1994, pp. 109-159.

18 Art. cit., p. 319.

19 Op. cit., p. 391. 
TABLA 1

Número de casos de indicativo y subjuntivo y porcentaje del uso de subjuntivo en interrogativas indirectas en cuatro textos antiguos (finales del s. XV-S. XVI)

\begin{tabular}{lccc}
\hline & indicativo & subjuntivo & \% subjuntivo \\
\hline Pulgar (ed. 1486) & 11 & 5 & 31 \\
Celestina (ed. 1514) & 20 & 12 & 38 \\
Lozana (ed. 1528) & 13 & 1 & 7 \\
Valdés (ed. 2a mitad s. xvI) & 16 & 2 & 11 \\
Total & 60 & 20 & 25 \\
\hline
\end{tabular}

TABLA 2

Número de casos de indicativo y subjuntivo y porcentaje del uso de subjuntivo en interrogativas indirectas en dos textos modernos del español peninsular

\begin{tabular}{lccc}
\hline & indicativo & subjuntivo & \% subjuntivo \\
\hline Madrid & 75 & 0 & 0 \\
Pérez-Reverte* & 13 & 0 & 0 \\
Total & 88 & 0 & 0 \\
\hline
\end{tabular}

La Tabla 1 confirma lo que constatan Woehr y Keniston acerca del modo verbal de las interrogativas indirectas: se usa tanto el indicativo como el subjuntivo, con una clara preferencia por aquél, dado que en ninguno de los textos analizados el porcentaje de subjuntivo llega a más del $38 \%{ }^{20}$. Además, parece que el uso de subjuntivo disminuye en el siglo xvi, lo que sería de esperar, aunque no en ese momento de acuerdo con el uso moderno.

* En la novela de Pérez-Reverte he encontrado dos casos del verbo ignorar. A pesar de que este verbo se compara muy bien con no saber, desde el punto de vista semántico y sintáctico, no han sido incorporados en el corpus los dos casos de ignorar por no corresponder a la estructura (7); como era de esperar, ambos presentan indicativo en la interrogativa subordinada.

${ }^{20}$ Es interesante que en el Poema de mio Cid sólo se registran casos de indicativo en oraciones interrogativas dependientes de no saber. Se trata de cinco casos en total. 
Siguiendo las observaciones de las gramáticas del español peninsular, ninguno de los textos modernos presenta casos de subjuntivo en las interrogativas indirectas. Es de notar que la diferencia de género no influye en el uso del modo verbal en ambos textos.

\section{LAS INTERROGATIVAS INDIRECTAS EN EL ESPAÑOL ANTIGUO Y MODERNO DE MÉXICO}

Si bien en el español de España se ha perdido la variación del modo verbal en las interrogativas indirectas, éste no es el caso en el español de México. Allí se registran con cierta frecuencia casos como:

(8) ...no sé que [sic] clase de broche de oro nos TENGAN preparado las grandes personalidades de la moda y la música ${ }^{21}$.

(9) No sési los PROTEJAN, pero en la historia han hecho grandes cosas, y por eso los hacen favoritos ${ }^{22}$.

Manuales importantes sobre el español de América que tratan explícitamente el español de México, no mencionan este uso del subjuntivo ${ }^{23}$. Lope Blanch ${ }^{24}$ se refiere brevemente al fenómeno en uno de sus artículos sobre el español de México, cuando trata la debilitación del futuro absoluto y enumera las estructuras y perífrasis que se usan en lugar de las formas de futuro. Según este autor, en oraciones interrogativas indirectas se prefiere el presente de subjuntivo al futuro. Es de notar que Lope Blanch ${ }^{25}$ ve este fenómeno como la manifestación de un proceso más general de reducción del paradigma verbal en el español de México. Moreno de Alba ${ }^{26}$ también encuentra casos

${ }^{21}$ H. Carrillo Cuevas, "Retro-grados", El Comal Virtual, en comal.com. $\mathrm{mx} /$ comal11/generacion.htm (23 de febrero de 2000).

${ }^{22}$ V. R. Ramos, "Arbitraje, otro rival", Públi.com, en publi.com/france98/mexico/mx02_0629.htm (23 de febrero de 2000).

23 Cf. E. G. Cotton, \& J. M. Sharp, Spanish in the Americas, Georgetown University Press, Washington, 1988, pp. 152-175; y J. M. Lipski, Latin American Spanish, Longman, London-New York, 1994, pp. 274-286.

${ }^{24}$ Estudios sobre el español de México, UNAM, México, 1972, p. 145.

25 Ibid., pp. 141-155.

26 Valores de las formas verbales en el español de México, UNAM, México, 1985, p. 135. 
de subjuntivo en interrogativas indirectas introducidas por no sé (si) en quince horas de entrevistas grabadas con habitantes de la Ciudad de México. Molho ${ }^{27}$, al tratar el modo verbal en las interrogativas indirectas en el español de España, señala, si bien de paso, el uso de subjuntivo en el habla mexicana.

Lo mismo que en el caso de España he reunido un corpus de ejemplos de la estructura (7) para el español de México, de lengua moderna y antigua. Como en el caso del español peninsular, para la lengua moderna he analizado lengua oral y escrita, ya que el corpus consta de una serie de entrevistas con habitantes de la Ciudad de México, provenientes de las clases culta y popular, y varios textos de Juan Rulfo ${ }^{28}$. Las entrevistas se llevaron a cabo en el marco del proyecto lingüístico del corpus del español de España.

El español mexicano antiguo se representa con un corpus de cartas fechadas todas en el siglo XVI, escritas en México por diferentes autores ${ }^{29}$. En gran parte coinciden cronológicamente con el corpus del español peninsular antiguo, de manera que será posible comparar el uso del modo verbal en las interrogativas indirectas en ambas variantes del español en la misma época. Por otra parte, he analizado la conocida novela de Fernández de Lizardi, El Periquillo Sarniento, de 1816, como representante del español mexicano del siglo $\mathrm{xIx}^{30}$, texto que sirve de etapa intermedia entre lengua antigua y moderna.

Los números y porcentajes relevantes se encuentran en las Tablas 3 y 4 :

27 Op. cit., p. 419.

${ }^{28}$ México culto: J. M. Lope Blanch, El habla de la Ciudad de México: Materiales para su estudio, UNAM, México, 1971; México popular: J. M. Lope BLANCH, El habla popular de la Ciudad de México: Materiales para su estudio, UNAM, México, 1976; J. Rulfo, Pedro Páramo. El llano en llamas, Planeta, Barcelona, 1986.

29 Documentos: C. Company Company, Documentos lingüisticos de la Nueva España (Altiplano Central), UNAM, México, [1525-1816; todas las cartas analizadas para el corpus datan del siglo XvI] 1994, pp. 23-239. El lenguaje de estas cartas a lo mejor no representa el español de México sino más bien el español en México, debido a que datan de una época colonial muy temprana y no se conoce el origen de los escritores ni la duración de su estancia en México.

${ }^{30}$ J. J. Fernández de Lizardi, El Periquillo Sarniento, ed. L. Sáinz de Medrano, Editora Nacional, Madrid, [1816] 1976. P. HenríQuez UreÑa califica esta novela junto con otra como "riquísimos archivos de la lengua popular mexicana" (“Observaciones sobre el español en América”, RFE, 8, 1921, p. 390). 
TABLA 3

Número de casos de indicativo y subjuntivo y porcentaje del uso de subjuntivo en interrogativas indirectas en el español moderno de México

\begin{tabular}{lccc}
\hline & indicativo & subjuntivo & $\%$ subjuntivo \\
\hline México culto & 28 & 7 & 20 \\
México popular & 45 & 13 & 22 \\
Rulfo & 21 & 1 & 5 \\
Total & 94 & 21 & 18 \\
\hline
\end{tabular}

TABLA 4

Número de casos de indicativo y subjuntivo y porcentaje del uso de subjuntivo en interrogativas indirectas en el español de México de los siglos XVI y XIX

\begin{tabular}{lccc}
\hline & indicativo & subjuntivo & \% subjuntivo \\
\hline Documentos (s. XvI) & 12 & 4 & 25 \\
Periquillo (1816) & 62 & 1 & 2 \\
\hline
\end{tabular}

En efecto, la Tabla 3 muestra que existe variación en el modo verbal en las interrogativas indirectas en el español moderno de México, si bien hay una clara preferencia por el indicativo ${ }^{31}$. Esto se corresponde, en líneas generales, con los resultados de Moreno de Alba ${ }^{32}$, quien, a raíz de los casos de subjuntivo que encontró en interrogativas indirectas con no sé, aplicó un cuestionario a cuarenta informantes en el que apuntaban si preferían el indicativo o subjuntivo en ciertas frases. Moreno de Alba encontró una proporción del $67 \%$ de indicativo frente al 33\% de subjuntivo, o del $55 \%$ de indicativo frente al $45 \%$ de subjun-

${ }^{31}$ La misma variación de modo se observa en el español de Venezuela donde "en ciertas cláusulas subordinadas a no sé (no sé si vaya a la fiesta)" también se usa el subjuntivo (M. SEDANo, "Sintaxis", EAc, 69, 1998, p. 72). No queda claro, del ejemplo citado por Sedano, sin embargo, si se trata aquí de una interrogativa indirecta o dubitativa (cf. sección 3, Tabla 5), ya que el sujeto de la forma verbal vaya puede ser el mismo que el de la frase principal.

32 Valores de las formas verbales en el español de México, p. 135. 
tivo dependiendo de la frase concreta. Recuérdese que la preferencia por el indicativo de la Tabla 3 la he observado en el español peninsular de finales de los siglos xv y xvI (cf. Tabla 1).

La Tabla 3 muestra igualmente que no hay diferencia entre los hablantes cultos y populares de la Ciudad de México por lo que se refiere al uso del subjuntivo; ambas clases presentan porcentajes muy parecidos (20\% y $22 \%$, respectivamente). Esto sugiere que el uso de subjuntivo en las interrogativas indirectas no está regido por motivos sociolingüísticos.

En cambio, es notable que en la obra de Rulfo, que en general presenta lenguaje popular, sólo haya encontrado un caso de subjuntivo en interrogativas indirectas negadas.

Los resultados de la Tabla 4 no son menos sorprendentes. Se ve, por un lado, que la variación estudiada en el presente artículo ya existía en el español de México del siglo xvi. Es interesante que los porcentajes de subjuntivo en las interrogativas indirectas en el español de México del siglo xvi y la época moderna sean casi iguales: $25 \%$ frente al $20 \%$ y $22 \%$ para México culto y México popular respectivamente y que éstos, a su vez, encajen muy bien con el correspondiente porcentaje para el español de los siglos Xv y xvI de España (25\%). Es decir que las tres muestras de lengua reflejan la misma tendencia en el uso de indicativo y subjuntivo en las interrogativas indirectas, con una preferencia por aquél. Por otro lado, en la novela de Fernández de Lizardi y en Rulfo, sólo he encontrado un ejemplo de subjuntivo ${ }^{33}$. Parece que en los textos no literarios el uso de subjuntivo suele prosperar, mientras que los textos literarios siguen más bien la norma peninsular moderna.

\section{AnÁlisis CUAlitativo de los EJEMPlos}

Cabe preguntarse ahora, una vez comprobada la variación de modo en las interrogativas indirectas, por qué en ciertos casos se usa el subjuntivo y en otros el indicativo.

33 Mientras que en el caso de Rulfo se trata de un ejemplo claro de subjuntivo ("Los grillos no sési TRUENEN", p. 116, r. 23), el caso de El Periquillo es dudoso ("no sé cómo HUBIERA SALIDO San Agustín con los maniqueos", cap. 10, p. 194), ya que también en el español peninsular actual el pluscuamperfecto de subjuntivo (hubiera salido) puede sustituir al condicional perfecto (habría salido). (Cf. Gramática descriptiva de la lengua española, t. 2, p. 2962.) 
En la introducción del presente artículo he indicado que, según las gramáticas del español moderno, el modo verbal de las interrogativas indirectas es el indicativo. No obstante, varios manuales presentan también ejemplos en los que el verbo de la subordinada, que depende del verbo saber negado, está en subjuntivo $^{34}$. Véase el ejemplo (10):

(10) No séqué te $D I G A^{35}$.

Según los manuales, en tales casos no se trata de oraciones interrogativas indirectas sino de interrogativas dubitativas ${ }^{36}$ o interrogativas deliberativas ${ }^{37}$. En éstas el sujeto de la principal y el de la subordinada son iguales, en tanto que en aquéllas esto no sucede necesariamente ${ }^{38}$. Además, las dubitativas no sólo admiten el subjuntivo sino también el infinitivo, lo que muestra el ejemplo (11):

(11) No séqué decirte $e^{39}$

Esta construcción sirve para expresar duda o indecisión por parte del sujeto ${ }^{40}$.

Bello señala que hay una diferencia semántica entre "No sé si salga" y "No sé si saldré", porque en el primer caso el hecho de la

34 Borrego et al., op. cit., pp. 112-113; Fernández Álvarez, op. cit., p. 48; Molno, op. cit., pp. 417-419; Gramática descriptiva de la lengua española, t. 2, pp. 2184-2185.

35 Borrego et al., op. cit., p. 113.

36 Gramática descriptiva de la lengua española, t. 2, pp. 2184-2185.

37 Borrego et al., op. cit., p. 112. A.-M. VANDERLYNDEN ("Sur l'interrogative indirecte au subjonctif en espagnol moderne", Hommage a Bernard Pottier, Klincksieck, Paris, 1988, t. 2, pp. 799-807) distingue cuatro tipos de gramática en que se trata el modo verbal de las interrogativas indirectas en el español actual: $i$ ) las que no discuten el modo verbal explícitamente pero que presentan ejemplos de indicativo y subjuntivo, ii) las que dan como único modo verbal el indicativo, iii) las que reconocen la alternancia de indicativo y subjuntivo y $i v$ ) las que distinguen entre oraciones interrogativas indirectas y dubitativas.

38 Señala Molho, op. cit., pp. 418-419, además, que sólo se da con primera persona singular ( $s e ̂$ ) o con se impersonal (se sabe) negativadas. No obstante, también presenta ejemplos en los que dichas condiciones justamente no se cumplen, ejemplos que califica de refinado arcaísmo (p. 420, nota 15$)$.

39 Borrego et al., op. cit., p. 113.

40 Matte Bon, op. cit., t. 1, p. 83; Borrego et al., op. cit., pp. 112-113. 
salida depende del mismo sujeto que todavía no ha tomado una decisión ${ }^{41}$. En el segundo caso, en cambio, el acto de salir no depende de la voluntad del sujeto sino de algún factor exterior.

$\mathrm{Al}$ calcular el porcentaje de subjuntivo frente al indicativo en nuestro corpus no he distinguido entre oraciones interrogativas indirectas y dubitativas, he tratado, en cambio, todos los ejemplos como casos de la estructura (7). Sin embargo, si en el español moderno peninsular hay variación de modo en lo que se refiere a las interrogativas indirectas y dubitativas, siendo el subjuntivo el modo de éstas, es posible que en nuestro corpus los casos de subjuntivo también se presenten en las interrogativas dubitativas de manera que se pueda explicar la variación de modo.

La Tabla 5 muestra la división de los ejemplos de subjuntivo en oraciones interrogativas indirectas y dubitativas en los textos que integran nuestro corpus, combinando los datos de las Tablas 1, 3 y 4 . Los casos en que la persona gramatical del verbo de la oración principal y la oración subordinada son iguales han sido contados como casos de interrogativas dubitativas; los demás, en que ambas personas gramaticales son diferentes, constituyen las interrogativas indirectas.

\section{TABLA 5}

Número de casos de subjuntivo en interrogativas indirectas y dubitativas en cuatro textos antiguos del español peninsular (finales del s. XV-S. XVI), en el español de México actual y en el español de México del s. XVI

\begin{tabular}{lcc}
\hline & indirectas & dubitativas \\
\hline Pulgar (ed. 1486) & 4 & 1 \\
Celestina (ed. 1514) & 6 & 6 \\
Lozana (ed. 1528) & 0 & 1 \\
Valdés (ed. 2a mitad s. xvI) & 2 & 0 \\
México culto & 5 & 2 \\
México popular & 11 & 2 \\
Documentos (s. xvI) & 4 & 0 \\
Total & 32 & 12 \\
\hline
\end{tabular}

${ }^{41}$ Gramática de la lengua castellana, EDAF, Madrid, 1982, p. 336. La edición más reciente de la gramática de la Real Academia Española (Gramática descriptiva de la lengua, t. 2, p. 2184) cita precisamente a Bello con respecto a este punto. 
Si bien resulta de la Tabla 5 que parte de los casos de subjuntivo ocurre en oraciones interrogativas dubitativas, es decir en oraciones que en español moderno emplearían el subjuntivo; quedan treinta y dos casos de subjuntivo que aparecen en oraciones interrogativas indirectas, cuyo uso de indicativo en español moderno es categórico. Es de notar que estos treinta y dos casos muestran una variedad de pronombres y adverbios interrogativos, además de la partícula si. Cabe buscar ahora una explicación para el uso de subjuntivo en interrogativas indirectas.

Afirma Bello, al contrario de la mayoría de los gramáticos, que "la interrogación indirecta admite por lo regular indicativo o subjuntivo, pero no siempre indistintamente" (p. 335). Según él, empleando el indicativo en la subordinada se afirma el acto o hecho expresado por el verbo, "el cual se enuncia algo dubitativamente por medio del subjuntivo" 42 .

Para Gili Gaya, en una oración como "No sé en qué haya consistido mi fracaso" (frente a "No sé en qué ha consistido mi fracaso") el subjuntivo "acentúa la incertidumbre del juicio" 43 .

Woehr ${ }^{44}$ postula algunas nociones semánticas muy generales para el uso de subjuntivo en interrogativas indirectas negadas en el español antiguo, las de hipótesis, deseo e indecisión. Además, en algunos casos sostiene que el subjuntivo es una característica estilística de la prosa española preclásica ${ }^{45}$.

Moreno de Alba, al tratar el modo verbal en las interrogativas indirectas, concluye simplemente que un cambio en el modo verbal "no parece afectar a la modalidad de la oración" 46.

De las observaciones de Bello y Gili Gaya, que parecen las más claras respecto al tema, se puede concluir que con el subjuntivo se pone en duda la realización o veracidad del acto expresado por el verbo de la subordinada ${ }^{47}$. Analizaré a conti-

42 Es probable que Bello, en realidad, no se refiera a las interrogativas indirectas sino a las dubitativas. A pesar de eso, parece relevante su observación acerca de la diferencia semántica entre el uso de indicativo y subjuntivo en la subordinada.

${ }^{43}$ Curso superior de sintaxis española, Biblograf, Barcelona, 1981, p. 136.

${ }^{44}$ Art. cit., pp. 321-322.

45 Por ejemplo, el uso frecuente de subjuntivo en interrogativas indirectas en Cárcel de amor, de Diego de San Pedro, Woenr lo considera un reflejo del estilo elegante del siglo Xv (art. cit., p. 320).

46 Valores de las formas verbales en el español de México, p. 135.

47 Moreno de Alba (El español en América, p. 176) justamente sostiene que con el futuro se puede expresar duda y cita un ejemplo de una interrogativa indirecta dependiendo de no sé: "no sé quién escribirá mejor". 
nuación algunos ejemplos concretos para ver si el criterio de la (no) realización o veracidad del verbo de la subordinada explica el uso de subjuntivo en los ejemplos de oraciones interrogativas indirectas.

El ejemplo (12) presenta una interrogativa indirecta introducida por quien con el verbo de la subordinada en subjuntivo:

(12) Yvuestras cosas, muy excelente reina e señora, no séyo quien tanto las PUEDA sublimar, que no haya mucho más trabajado el obrador que puede decir el escritor ${ }^{48}$.

En la Letra XI, Fernando del Pulgar se dirige a la reina Isabel la Católica señalando la trascendencia de poner por escrito sus muchas obras importantes. Añade Pulgar que en algunos casos los historiadores presentaron los hechos mejores de lo que en realidad eran; sin embargo, estima, en el ejemplo (12), en el caso de la reina será difícil hinchar o embellecer los hechos, por la importancia y grandeza de los mismos. No sólo Pulgar dice no conocer a nadie que pueda sublimar las obras de la reina, también pone en duda la posibilidad de sublimación de los hechos. El motivo de la afirmación es doble: por una parte halaga a la reina, elogiando sus obras que, por ser tan buenas, ningún escritor puede exagerar, y, por otra, le pide perdón porque es posible que él no sea capaz de presentarlas debidamente. Más adelante vuelve sobre este punto al decir "yo confieso, señora, que ha menester mejor cabeça que la mía para las poner en memoria perpetua, pues son dellas dignas" 49 .

De la misma obra de Fernando del Pulgar proviene el ejemplo (13). En éste veo la misma estructura que en (12), es decir una interrogativa indirecta introducida por quien, aunque ahora el verbo de la subordinada está en indicativo.

(13) A las otras cosas que tocáis de la Sacra Escritura no os respondo, porque no sé quien sois; aclaraos y satisfaceros he cuanto pudiere ${ }^{50}$.

48 Pulgar, Letra XI, p. 57, 1. 10. A pesar de que quien aquí no lleva acento escrito, creo que se trata de un pronombre interrogativo y no de relativo. Se puede sustituir el quien aquí por qué persona y no por la persona que. Véase más adelante la discusión acerca de los ejemplos (18) y (19).

49 Pulgar, Letra XI, p. 58, r. 2-3.

50 Pulgar, Letra XXI, p. 97, 1. 16. 
En la Letra XXI, Pulgar se defiende de una serie de acusaciones que un escritor anónimo le ha hecho en una carta. Después de haber tratado las diferentes acusaciones, Pulgar empieza el último párrafo de su letra con el ejemplo (13). Se niega a tratar las acusaciones por desconocer la identidad del autor. El uso del indicativo sois en la subordinada es muy apropiado aquí, puesto que Pulgar no duda de la existencia del autor anónimo - ha recibido una carta de él-, es decir no niega el hecho expresado por el verbo de la subordinada, simplemente señala que no sabe quién es el autor anónimo, no lo conoce, lo que le sirve de justificación para no discutir el resto de los temas de la carta.

Los ejemplos (12) y (13), por lo tanto, ilustran muy bien el uso de subjuntivo frente al indicativo en las interrogativas indirectas ya que en los dos casos se puede argumentar, con base en un contexto más amplio, el valor funcional y comunicativo de ambos modos.

La misma diferencia de significado entre indicativo y subjuntivo en la interrogativa indirecta se observa en las cartas mexicanas del siglo xvi. En el siguiente ejemplo, el autor usa tanto un indicativo como un subjuntivo en dos interrogativas indirectas coordinadas.

(14) ...porque como en esa flota se perdieron tantos nabíos, estoy con muy gran pe..., que no sé si se quedaron allá, o si, por mis pecados, les HAYA aconteçido algo por la mar51.

La carta se fecha en 1572 sin que se indique lugar de procedencia, y es de una tal Juana Bautista que escribe a su hermana preguntando por unos parientes que iban a viajar a México. Al llegar la flota, sus parientes no aparecen, por lo que la mujer se preocupa. El ejemplo muestra dos interrogativas indirectas que dependen de no sé si y que están relacionadas por medio de la conjunción coordinante $o$. En la primera interrogativa indirecta (si se quedaron allá) la autora emplea un indicativo afirmando así la acción de quedarse allá, es decir en España. En cambio, en la segunda interrogativa indirecta (si, por mis pecados, les haya aconteçido algo por la mar) emplea un subjuntivo, con lo cual acentúa la incertidumbre de su juicio de haberles aconteçido algo 
por la mar. El efecto del indicativo y subjuntivo respectivamente es tranquilizador. Si la autora puede optar por un indicativo o un subjuntivo, opta por el subjuntivo para poner en duda la idea de que sus parientes puedan haber fallecido durante el viaje, en tanto que al emplear un indicativo presenta como más firme la idea de que simplemente se quedaron en España y que, por lo tanto, no les habrá pasado nada grave.

Igual que en los ejemplos (12) y (13), por lo tanto, veo en (14) que el uso de indicativo y subjuntivo en las interrogativas indirectas sirve a un fin comunicativo muy claro y que ambos modos son sumamente funcionales; su valor comunicativo en las interrogativas indirectas, tal como se refleja en los ejemplos del español antiguo de España y México, se ha conservado en el español mexicano actual. Compárense (15) y (16), ambos tienen su origen en nuestro corpus de entrevistas hechas con hablantes cultos de la Ciudad de México:

(15) -Bueno, mira: nunca sabes para un torero qué SEA peor ¿eh?52

(16) ...y le había yo dicho: "Madre, yo no me siento a gusto en el mundo. Yo no séqué me pasa"53.

En el ejemplo (15), con un subjuntivo en la interrogativa indirecta, se trata del torero Joselito a quien luego de regalar unas joyas a la Virgen de la Moreneta lo mató un toro. La informante que observa lo citado en (15) se pregunta si la muerte del torero fue a pesar del regalo o justamente a causa de ello, ya que "puede ser que haya sido un beneficio que le dio la Virgen en lugar de... pensar que lo descuidó: Un torero que se muere en el ruedo... se consagra". Al usar subjuntivo en la interrogativa indirecta, la informante expresa que no está segura de su juicio acerca de la mala suerte del torero, que quizá el torero no haya tenido tan mala suerte, puesto que su muerte precisamente le ha dado cierta fama.

El ejemplo (16) es parte de un fragmento en el que la informante, destinada a ser monja, va a hablar con la Madre del colegio porque duda de su vocación. Este ejemplo puede considerarse pareja del (15), que también presenta una interrogativa indirecta introducida por el pronombre qué, mientras que el 
verbo de la subordinada está en indicativo. Y, efectivamente, es muy apropiado el uso de indicativo en (16), con el que el hablante afirma la actividad expresada por el verbo pasar, no hay motivo para poner en duda que algo le pase, pues ella lo experimenta en carne viva, y las dudas que tiene acerca del camino a seguir aparentemente la atormentan.

Como he dicho, en el español actual de España sólo se usa el indicativo en las interrogativas indirectas, algo que ha sido comprobado por los datos de la Tabla 2. Hay que concluir, por ello, que el mecanismo de duda de la acción del verbo de la subordinada ya no opera en el español peninsular, tal como lo hacía en la lengua antigua, y sigue haciéndolo, en cambio, en el español mexicano actual. No obstante, en un cuento de Juan Marsé encontramos el siguiente ejemplo, que parece ser un caso único:

(17) Al parecer falta un contertulio, pero no sabemos quién PUEDA ser ${ }^{54}$.

El ejemplo figura en el cuento "El caso del escritor desleído", que trata sobre un escritor que en cierto momento empieza a desvanecerse, hasta que, literalmente, desaparece por completo. En la escena de la que proviene el ejemplo, el escritor participa en una mesa redonda con otros escritores, pero está tan borroso que casi nadie nota su presencia. El moderador, quien señala la ausencia de un participante - el escritor desleído-, indica con el subjuntivo de la interrogativa indirecta que no está seguro de que realmente falte alguien. Por medio del subjuntivo acentúa sus dudas acerca de la identidad o existencia de ese contertulio, duda muy fundada, en este caso, puesto que el hombre en cuestión se ha esfumado casi por completo.

A pesar de que, al parecer, el uso de subjuntivo en un ejemplo como (17) es sumamente raro en el español actual de Espa$\tilde{\text { na }}{ }^{55}$, es posible que se deba a contaminación con otra clase de

54 Marsé, p. 147, 1. 6. Además del ejemplo citado, en el cuento sólo hay un caso más de la estructura (7), en el que el verbo de la interrogativa indirecta está en indicativo.

$55 \mathrm{Al}$ presentar este ejemplo a dos nativohablantes ambas dijeron que el uso del subjuntivo no les parecía muy extraño. Las dos coincidían en que con el subjuntivo se transmitía mayor duda. 
oración en la que el uso de subjuntivo, en cambio, sí sea muy frecuente. Me refiero a oraciones subordinadas de relativo en las que el antecedente es desconocido o no específico. Dichas oraciones pueden ser introducidas por un pronombre relativo con antecedente implícito, tal como muestra el ejemplo (18):

(18) Recordaremos a quienes nos AYUDEN56.

Es obvio que el ejemplo (17), desde el punto de vista estructural y semántico, se parece mucho a ejemplos como (18), ya que en ambos la subordinada se introduce por quien(es), que en (17) desempeña el papel de pronombre interrogativo, en tanto que en (18) funciona como un pronombre relativo. Además, en ambas oraciones quien(es) se refiere a una entidad humana desconocida. En vista de la existencia de oraciones como (18), por lo tanto, el uso de subjuntivo en (17) incluso es más comprensible ${ }^{57}$.

\section{COMPROBACIÓN CUANTITATIVA DE LA HIPÓTESIS}

Nuestra hipótesis, puesta a prueba en la sección anterior con una serie de ejemplos, postula que en las oraciones interrogativas indirectas se usa el indicativo para afirmar la actividad o el hecho expresado por el verbo de la subordinada, en tanto que con el subjuntivo se pone en duda su realización o veracidad.

Para comprobar esta hipótesis de manera independiente, es decir con base en un criterio que no guarde relación directa con el modo verbal usado, me fijaré en dos aspectos de las formas verbales que surgen en las interrogativas indirectas, a saber el tiempo verbal y la persona gramatical.

5.1. Tiempo verbal. En vista de nuestra hipótesis es de esperar que el subjuntivo aparezca más en un tiempo verbal que lo

56 Fernández Áluarez, op. cit., p. 91.

${ }^{57}$ La contaminación discutida aquí a raíz del pronombre quien puede darse teóricamente con todos los pronombres y adverbios interrogativos que a la vez sirven de relativos. Dice la Real Academia Española que "Los pronombres, adjetivos y adverbios interrogativos que introducen la interrogación indirecta no se diferencian formalmente de los relativos salvo en que tienden a pronunciarse con mayor intensidad y en que llevan una tilde en la escritura" (Gramática descriptiva de la lengua española, t. 2, p. 2187). 
hace al presente o futuro que en uno que lo hace al pasado. Como con el subjuntivo se pone en duda la realización o veracidad del acto expresado en la subordinada, es más coherente y lógico que suceda con un acto presente o futuro que con uno pasado, puesto que los hechos pasados ya son conocidos.

Para este cálculo he dividido los corpora de México culto y popular por tiempo verbal usado en la interrogativa indirecta; bajo la categoría "presente/futuro" he agrupado, además de estas formas verbales, el pretérito perfecto, dado que éstas expresan una acción en relación directa con el momento de habla $^{58}$. Bajo la categoría "pasado" caben el pretérito indefinido e imperfecto, el pluscuamperfecto y el condicional. En las Tablas 6 y 7 se presentan los resultados:

TABLA 6

Uso de formas verbales presentes y futuras frente a pasadas en indicativo y subjuntivo en interrogativas indirectas en México culto

\begin{tabular}{lcc}
\hline & presente/futuro & pasado \\
\hline indicativo & $78 \%(18)$ & $100 \%(10)$ \\
subjuntivo & $22 \%(5)$ & $0 \%(0)$ \\
\hline
\end{tabular}

TABLA 7

Uso de formas verbales presentes y futuras frente a pasadas en indicativo y subjuntivo en interrogativas indirectas en México popular

\begin{tabular}{lcc}
\hline & presente/futuro & pasado \\
\hline indicativo & $63 \%(19)$ & $100 \%(26)$ \\
subjuntivo & $37 \%(11)$ & $0 \%(0)$ \\
\hline
\end{tabular}

De las Tablas 6 y 7 resulta claramente que, como esperábamos, el subjuntivo se usa más para referirse al presente o futuro que al pasado. En efecto, no he encontrado en ambos corpora ningún caso de subjuntivo en pasado.

58 Gramática descriptiva de la lengua española, t. 2, p. 2941. 
5.2. Persona gramatical. Además del tiempo verbal de las interrogativas indirectas, puede ser interesante analizar la persona gramatical del verbo de las interrogativas indirectas por lo que ésta influye en el uso del modo verbal. En una situación comunicativa, el hablante puede referirse a sí mismo, al interlocutor o a una tercera persona fuera de la situación de habla. Comparando estos tres participantes, es de esperar que un hablante use más el subjuntivo en una interrogativa indirecta al referirse -mediante la terminación del verbo de la subordinada- al interlocutor que cuando alude a sí mismo o a una tercera persona, dado que al expresar un acto realizado por el interlocutor puede ser comunicativamente útil o apropiado poner en duda el acto. Me refiero a ejemplos como (19):

(19) -Bueno, no sési usted lo HAYA observado 59 .

En ese caso se trataría de una estrategia comunicativa de cortesía - puede ser que el hablante no tenga razón en atribuir cierto acto al interlocutor-, por ejemplo, para no ofender al interlocutor. El uso de subjuntivo en este tipo de oraciones como recurso de cortesía se corresponde con las observaciones de la Real Academia Española, que sostiene que puede usarse el subjuntivo en las interrogativas indirectas en situaciones de cortesía ${ }^{60}$.

Para realizar este cálculo he dividido los ejemplos de México culto y México popular en formas verbales que se refieren al interlocutor (tú, usted[es]) frente a otras formas verbales. En cada categoría he calculado el porcentaje de indicativo y subjuntivo. Las Tablas 8 y 9 muestran los resultados:

TABLA 8

Uso de formas verbales de tú/usted(es) frente a otras personas gramaticales en indicativo y subjuntivo en México culto

\begin{tabular}{lcl}
\hline & tú/usted(es) & \multicolumn{1}{c}{ otros } \\
\hline indicativo & $75 \%(3)$ & $86 \%(25)$ \\
subjuntivo & $25 \%(1)$ & $14 \%(4)$ \\
\hline
\end{tabular}

59 México culto, muestra XXI.

${ }^{60}$ Gramática descriptiva de la lengua española, t. 2, p. 2185. Es de notar que para ilustrar el uso de cortesía se cita un ejemplo (131a) con preguntar si, en tanto que a raíz del ejemplo que corresponde a nuestra estructura (7) (131b) se habla del uso especulativo. 
TABLA 9

Uso de formas verbales de tú/usted(es) frente a otras personas gramaticales en indicativo y subjuntivo en México popular

\begin{tabular}{lcc}
\hline & tú/usted(es) & otros \\
\hline indicativo & $40 \%(2)$ & $84 \%(43)$ \\
subjuntivo & $60 \%(3)$ & $16 \%(8)$
\end{tabular}

Las Tablas 8 y 9 señalan que la expectativa del uso más frecuente del subjuntivo para referirse al interlocutor y no a otra persona gramatical se cumple, aunque en México culto la diferencia entre los respectivos porcentajes no es muy grande (el $25 \%$ de subjuntivo con tú/usted[es] frente al $14 \%$ con otros participantes). En cambio, México popular sí muestra una diferencia clara entre ambos porcentajes (el 60\% frente al 16\%). Es de notar, sin embargo, que en algunas categorías los porcentajes están calculados sobre números muy bajos.

No obstante, en dos de los cuatro casos de subjuntivo que se refieren a otra persona gramatical en México culto está presente un complemento indirecto que remite a tú/usted(es). Asimismo, en México popular, entre los ocho casos de subjuntivo que se refieren a otra persona gramatical hay uno en que el complemento indirecto sugiere al interlocutor. Véase el ejemplo (20) donde al verbo de la subordinada lo acompaña un complemento indirecto que alude al interlocutor:

(20) ...no sési te HAYA dicho Chole que mi mamá estuvo bastante mal ${ }^{61}$.

Dado que en esos casos el complemento indirecto, además del sujeto, está involucrado en la acción de forma relativamente activa ${ }^{62}$ y se refiere al interlocutor; o sea, dado que en esos casos también el interlocutor está claramente presente, el hablante puede juzgarlo apropiado, por motivos de cortesía, o poner en duda la acción expresada por el verbo de la interro-

${ }^{61}$ México culto, muestra XII.

62 Cf. E. C. GARCía, The role of theory in linguistic analysis: The Spanish pronoun system, North-Holland, Amsterdam-Oxford, 1975, pp. 66-67, entre otros. 
gativa indirecta, igual que en los casos en los que el verbo remite al interlocutor.

Ahora bien, si incluimos estos casos en el grupo de tú/usted(es), porque es posible que en ellos funcione la misma estrategia comunicativa, la diferencia de porcentajes se hace más tajante, como muestran las Tablas 10 y 11 :

TABLA 10

Uso de formas verbales de tú/usted(es), presencia de complemento indirecto de tú/usted(es) frente a otras personas gramaticales en indicativo y subjuntivo en México culto

\begin{tabular}{lcc}
\hline & tú/usted(es) & otros \\
\hline indicativo & $50 \%(3)$ & $93 \%(25)$ \\
subjuntivo & $50 \%(3)$ & $7 \%(2)$ \\
\hline
\end{tabular}

TABLA 11

Uso de formas verbales de tú/usted(es), presencia de complemento indirecto de tú/usted(es) frente a otras personas gramaticales en indicativo y subjuntivo en México popular

\begin{tabular}{lcc}
\hline & tú/usted(es) & otros \\
\hline indicativo & $33 \%(2)$ & $86 \%(43)$ \\
subjuntivo & $67 \%(4)$ & $14 \%(7)$ \\
\hline
\end{tabular}

En México culto el uso de subjuntivo para aludir al interlocutor ha subido al $50 \%$ frente al $7 \%$ para referirse a otra persona. En México popular los respectivos porcentajes han cambiado menos dramáticamente (el $67 \%$ frente al 14\%), puesto que se trata aquí de un solo ejemplo de interlocutor como complemento indirecto.

Los datos de las Tablas 6 a 11 corroboran de forma cuantitativa la hipótesis acerca del valor del subjuntivo en las interrogativas indirectas, pues en el cálculo del tiempo verbal y de la persona gramatical del verbo el porcentaje de subjuntivo es más alto donde es más lógico o apropiado poner en duda la realización o veracidad del acto de la interrogativa indirecta. 


\section{Conclusión}

En este artículo he discutido el modo verbal en las oraciones interrogativas indirectas encabezadas por el verbo saber negado. Hemos visto que, mientras que en el español actual peninsular sólo se usa el indicativo, en el español peninsular de finales de los siglos Xv y xvI era bastante frecuente el uso de subjuntivo y que, por lo tanto, se ha efectuado un cambio lingüístico a lo largo de la historia. No está claro, todavía, cuándo cayó en desuso el subjuntivo en las interrogativas indirectas, pero nuestros datos sugieren que en el curso del siglo XvI el subjuntivo perdió terreno a favor del indicativo.

Los datos que he reunido del español de México, de lengua antigua y actual, apuntan a que las interrogativas indirectas han tomado un rumbo distinto al otro lado del Atlántico. Hemos visto que en el español mexicano del siglo xvi el uso del subjuntivo en este tipo de oraciones era bastante frecuente, lo mismo que en el español peninsular de la misma época, y que en México no se ha perdido la variación de modo a lo largo de los siglos.

En términos de Rona ${ }^{63}$, que sostiene que la lengua es un diasistema que consta de un eje diacrónico, uno diatópico y uno diastrático, es decir que la lengua está determinada por relaciones que cambian a través del tiempo de un lugar a otro y de un nivel sociocultural a otro, el cambio lingüístico que he estudiado se puede caracterizar como un cambio en el eje diacrónico (español peninsular de finales de los siglos xv y xVI frente a español peninsular actual) como en el eje diatópico (español peninsular frente a español mexicano). En cambio, los datos de los corpora de México culto y México popular sugieren que no hay diferencia de uso en el eje diastrático.

También he comprobado, con base en la discusión de varios ejemplos del español peninsular y mexicano, que el uso de uno y otro modo estaba motivado pragmáticamente y que en cada caso servía a un fin comunicativo muy específico. Mientras que con el indicativo el hablante afirma la actividad o el hecho expresado por el verbo de la subordinada, con el subjuntivo pone en duda su realización o veracidad. Es interesante, a mi parecer, que con este principio general se pueda explicar la variación del modo verbal en el español peninsular

63 “¿Qué es un americanismo?”, El Simposio de México (enero de 1968), UNAM, México, 1969, pp. 135-148. 
de finales de los siglos XV y xvi y en el español mexicano del siglo xvi y de la época moderna.

Asimismo, he corroborado mi hipótesis acerca del valor del subjuntivo en el cálculo del tiempo verbal y la persona gramatical de la subordinada, cálculos en los que el porcentaje de subjuntivo era más alto donde, desde el punto de vista comunicativo, era más lógico o apropiado poner en duda la realización o veracidad del acto de la subordinada.

A raíz del cálculo de la persona gramatical de la subordinada, he argumentado que se trata de una estrategia de cortesía, o sea que el uso de subjuntivo constituye un recurso comunicativo por parte del hablante para expresarse de forma cortés hacia su interlocutor. Esto quizás pueda explicar el hecho de que en los corpora de lengua oral, México culto y México popular, el uso de subjuntivo en interrogativas indirectas sea mucho más frecuente que en la obra de Juan Rulfo. Si bien ésta se caracteriza por el empleo de un lenguaje popular, se trata de lengua escrita, literaria. Es de esperar que las situaciones de cortesía, cuando el interlocutor realmente está presente, se den más en lengua oral que en la escrita y que, por consiguiente, sea en lengua oral donde será particularmente relevante el empleo del subjuntivo.

Podemos preguntarnos si la variación del modo verbal en el español de México actual procede directamente de la misma variación en el español peninsular del siglo xvi. Esto encajaría con la opinión de Lapesa ${ }^{64}$, compartida por muchos otros ${ }^{65}$, de que el español de América mantiene una serie de arcaísmos morfológicos y sintácticos. Justificarían tal visión los porcentajes de subjuntivo parecidos para el español peninsular de los siglos XV y XVI, para el español mexicano del siglo XVI y actual y el hecho de que en los ejemplos de las diferentes muestras de lengua la motivación del uso de subjuntivo parece ser igual ${ }^{66}$.

64 Op. cit., p. 583.

65 Por ejemplo, A. Zamora Vicente afirma que "el fondo patrimonial idiomático aparece vivamente coloreado por el arcaísmo", que "el voseo no es otra cosa que un rígido arcaísmo" y que "el léxico americano es... abundante en arcaísmos" (Dialectología española, Gredos, Madrid, 1970, pp. 378, $407,423)$.

${ }^{66}$ Cf., en cambio, Lope Blanch (Estudios sobre el español de México, pp. 2949) que en un artículo titulado "El supuesto arcaísmo del español americano" se opone a la idea de que el español de América sea arcaizante y conservador. 
Por otra parte, siguiendo a Moreno de Alba ${ }^{67}$, también se podría ver la pérdida del uso de subjuntivo en las interrogativas indirectas en el español peninsular actual como un caso de empobrecimiento, dado que la lengua de la mayoría de los hispanohablantes (los hispanoamericanos) mantiene ciertas formas que se han perdido en la lengua de la minoría (los españoles). Lo que aboga en contra de la idea de que la variación del modo verbal en el español mexicano actual sea un arcaísmo es el hecho de que en México el uso de subjuntivo en la lengua oral, por lo menos en parte, sirve como recurso de cortesía. A pesar de que faltan datos para el español peninsular antiguo, a causa de la ausencia de muestras de lengua oral auténtica, el uso mexicano del subjuntivo en las oraciones interrogativas indirectas sugiere más bien que se ha tomado una estructura ya existente para usarla en un nuevo contexto pragmático, con un nuevo fin comunicativo, mecanismo cuya operación también se ha identificado en otras áreas de la gramática del español mexicano ${ }^{68}$.

Dorien Nieuwenhuijsen Universität aus Utrecht, Holländ

67 El español en América, p. 101, nota 101.

68 Cf. C. Company Company, "La engañosa apariencia sintáctica del español americano. ¿Conservador o innovador?”, FHA, 2000, núm. 17, 15-26. A raíz del uso de las duplicaciones posesivas del tipo su mujer de Juan en el español mexicano actual, Company Company también argumenta que se trata de una vieja estructura usada con un nuevo valor semántico; en la nota 7 ofrece más ejemplos del mismo mecanismo. 